\title{
Generation and analysis of expression sequence tags from haustoria of the wheat stripe rust fungus Puccinia striiformis f. sp. Tritici Chuntao Yin ${ }^{1}$, Xianming Chen ${ }^{1,2}$, Xiaojie Wang ${ }^{3}$, Qingmei Han ${ }^{3}$, Zhensheng Kang ${ }^{3}$ and Scot H Hulbert*1
}

Address: ${ }^{1}$ Department of Plant Pathology, Washington State University, Pullman, WA 99164-6430, USA, ${ }^{2}$ US Department of Agricultural Research Service, Wheat Genetic, Quality, Physiology and Disease Research Unit, Pullman, WA 99164-6430, USA and ${ }^{3}$ College of Plant Protection and Shaanxi Key Laboratory of Molecular Biology for Agriculture, Northwest A\&F University, Yangling, Shaanxi, 712100, PR China

Email: Chuntao Yin - chunto_yin@wsu.edu; Xianming Chen - xianming@wsu.edu; Xiaojie Wang - sealover2001@gmail.com; Qingmei Han - hanqm9@163.com; Zhensheng Kang - kangzs@nwsuaf.edu.cn; Scot H Hulbert* - scot_hulbert@wsu.edu

* Corresponding author

Published: 23 December 2009

BMC Genomics 2009, 10:626 doi:10.1186/147|-2164-10-626
Received: 17 June 2009

Accepted: 23 December 2009

This article is available from: http://www.biomedcentral.com//47/-2/64//0/626

(c) 2009 Yin et al; licensee BioMed Central Ltd.

This is an Open Access article distributed under the terms of the Creative Commons Attribution License (http://creativecommons.org/licenses/by/2.0), which permits unrestricted use, distribution, and reproduction in any medium, provided the original work is properly cited.

\begin{abstract}
Background: Stripe rust, caused by Puccinia striiformis f. sp. tritici (Pst), is one of the most destructive diseases of wheat (Triticum aestivum L.) worldwide. In spite of its agricultural importance, the genomics and genetics of the pathogen are poorly characterized. Pst transcripts from urediniospores and germinated urediniospores have been examined previously, but little is known about genes expressed during host infection. Some genes involved in virulence in other rust fungi have been found to be specifically expressed in haustoria. Therefore, the objective of this study was to generate a cDNA library to characterize genes expressed in haustoria of Pst.

Results: A total of 5, I 26 EST sequences of high quality were generated from haustoria of Pst, from which 287 contigs and 847 singletons were derived. Approximately $10 \%$ and $26 \%$ of the I,I34 unique sequences were homologous to proteins with known functions and hypothetical proteins, respectively. The remaining $64 \%$ of the unique sequences had no significant similarities in GenBank. Fifteen genes were predicted to be proteins secreted from Pst haustoria. Analysis of ten genes, including six secreted protein genes, using quantitative RT-PCR revealed changes in transcript levels in different developmental and infection stages of the pathogen.

Conclusions: The haustorial cDNA library was useful in identifying genes of the stripe rust fungus expressed during the infection process. From the library, we identified 15 genes encoding putative secreted proteins and six genes induced during the infection process. These genes are candidates for further studies to determine their functions in wheat-Pst interactions.
\end{abstract}

\section{Background}

Rust fungi are a large group of obligately biotrophic basidiomycete fungi that completely depend on their living host tissue for growth and reproduction. Wheat (Triticum aestivum L.) is a host to three different rust fungi, causing stripe (yellow), leaf (brown) and stem (black) rust. Wheat stripe rust, caused by Puccinia striiformis Westend. f. sp. tritici Eriks. (Pst), is a serious problem in all major wheat growing countries $[1,2]$. In the United States, the disease is most destructive in the western United States and has become increasingly important in the south-central and south-eastern states $[1,3,4]$. Unlike the stem rust $(P$. 
graminis f. sp. tritici) and leaf rust (P. triticina) fungi, Pst does not have a known alternate host to complete the sexual cycle. During infection, urediniospores of Pst germinate on wheat leaf surfaces to produce germ tubes. Depending upon the isolate, Pst forms noticeable or unnoticeable appressoria [5,6], from which an infection peg is formed and penetrates a leaf stoma, followed by infection hyphae that form haustorial mother cells, and a specialized infection structure called the haustorium forms and an intimate feeding relationship is established. Haustoria are essential for rust fungi to take nutrients from their host $[7-10]$ and have also been shown to be involved in vitamin synthesis [11].

Plant disease resistance relies on the recognition of pathogen avirulence (Avr) gene products by host resistance (R) genes through either direct (receptor-ligand model) or indirect (guard model) association, which induces defense responses. Haustoria play an essential role in the reactions of plants with rust fungi. For example, four avirulence genes from Melampsora lini, the flax rust pathogen, have been cloned and found to encode small secreted proteins expressed in the fungal haustoria [12,13]. A large number of plant-induced and haustorium-specific genes have been identified in the bean rust fungus Uromyces fabae $[14,15]$. To date, there are no reports of cloning and molecular characterization of either virulence or avirulence genes from any of the cereal rust pathogens.

The stripe rust fungus lacks several features to be an ideal model system for genetic analysis. It does not have a known alternate host for completing the sexual cycle. Like the other cereal rusts, Pst is very difficult to culture in vitro and stable transformation systems are yet to be developed. While molecular and genetic approaches are currently lacking, some advances are being made in genomics. Recently Ling et al. [16] constructed a fulllength cDNA library of Pst from RNA extracted from urediniospores and identified some genes encoding protein products that maybe involved in virulence or infection. Some genes highly expressed in germinated urediniospores of the fungus were also reported [17]. Our understanding of the molecular mechanisms underlying infection and development within host tissue is still very limited. A haustorium is a hub of cellular communication between the host and the pathogen for the establishment of a biotrophic relationship. To gain some insights into haustorium-related functions and investigate Pst virulence mechanisms, we constructed a Pst haustorial cDNA library based on a protocol for the preparative isolation of haustoria from rust-infected leaves [18] and searched for expressed sequence tags (ESTs) encoding putative secreted proteins. More than 5,000 ESTs from the haustorial cDNA library were generated. Fifteen unique sequences were predicted to encode proteins secreted from haustoria. Quan- titative real-time PCR (qRT-PCR) studies revealed that some cDNAs were specifically expressed in planta.

\section{Results}

\section{Construction of a haustorial cDNA library}

Stripe rust haustoria were isolated from heavily infected wheat leaves. Total RNA was extracted from haustoria of race PST-78 of Pst and a cDNA library was constructed with the pDNR-LIB vector. Most of the cloned cDNA inserts in this library were between 300-1,500 bp in size. A total of 6,000 random cDNA clones were sequenced from the 5 ' end, from which 5,126 high quality ESTs were obtained. While the sequencing reactions covered the full inserts of many of the smaller clones, 687 of the clones with larger inserts were also sequenced from the 3 ' end.

\section{EST sequence analysis}

The EST sequences were subjected to BLAST searches (described in methods). Of the 5,126 sequences, 1,420 sequences were found to be likely of plant origin as indicated by significant BLAST scores (E value $\leq 10^{-5}$ ) to plant sequences but little or no homology to other organisms. After removing contaminating plant sequences, 3,706 sequences were assembled into 1,134 unique sequences, of which 847 were singletons and 287 were contigs represented by multiple clones at frequencies ranging from 2 to 873. A majority of the contigs contained two, three or four sequences. The frequency of redundant ESTs was shown in Figure 1. The average $\mathrm{G}+\mathrm{C}$ content of these unique sequences was $43.11 \%$, which was similar to the $\mathrm{G}+\mathrm{C}$ content of ESTs in P. graminis and Pst germinated urediniospores $[17,19]$. The sequences were deposited in the NCBI dbEST sequence database (Accession numbers GH737012 - GH738498).

All unique sequences were used in homology searches of the NCBI non-redundant protein sequences and the $P$. graminis genome database using the BLASTX and BLASTn algorithm. Unique sequences with significant homology $\left(\mathrm{E} \leq 10^{-5}\right)$ to known proteins were grouped according to their putative functions [see additional files 1 and 2]. Of the 1,134 unique sequences, only $109(10 \%)$ showed significant similarities to proteins of known function, 296 (26\%) showed significant similarities to predicted proteins of unknown function and 729 (64\%) showed no significant similarity to a database entry. Based on the examination of the significant sequence similarity to a database entry, a putative functional category was assigned to the specific unisequence. The majority of the genes were predicted to code for proteins of unknown function (Figure 2). The largest group of genes with known functions showed similarities to ribosomal proteins, followed by the group of genes with similarities to proteins involved in primary metabolism and energy production. Some unisequences matched ESTs from Pst ured- 


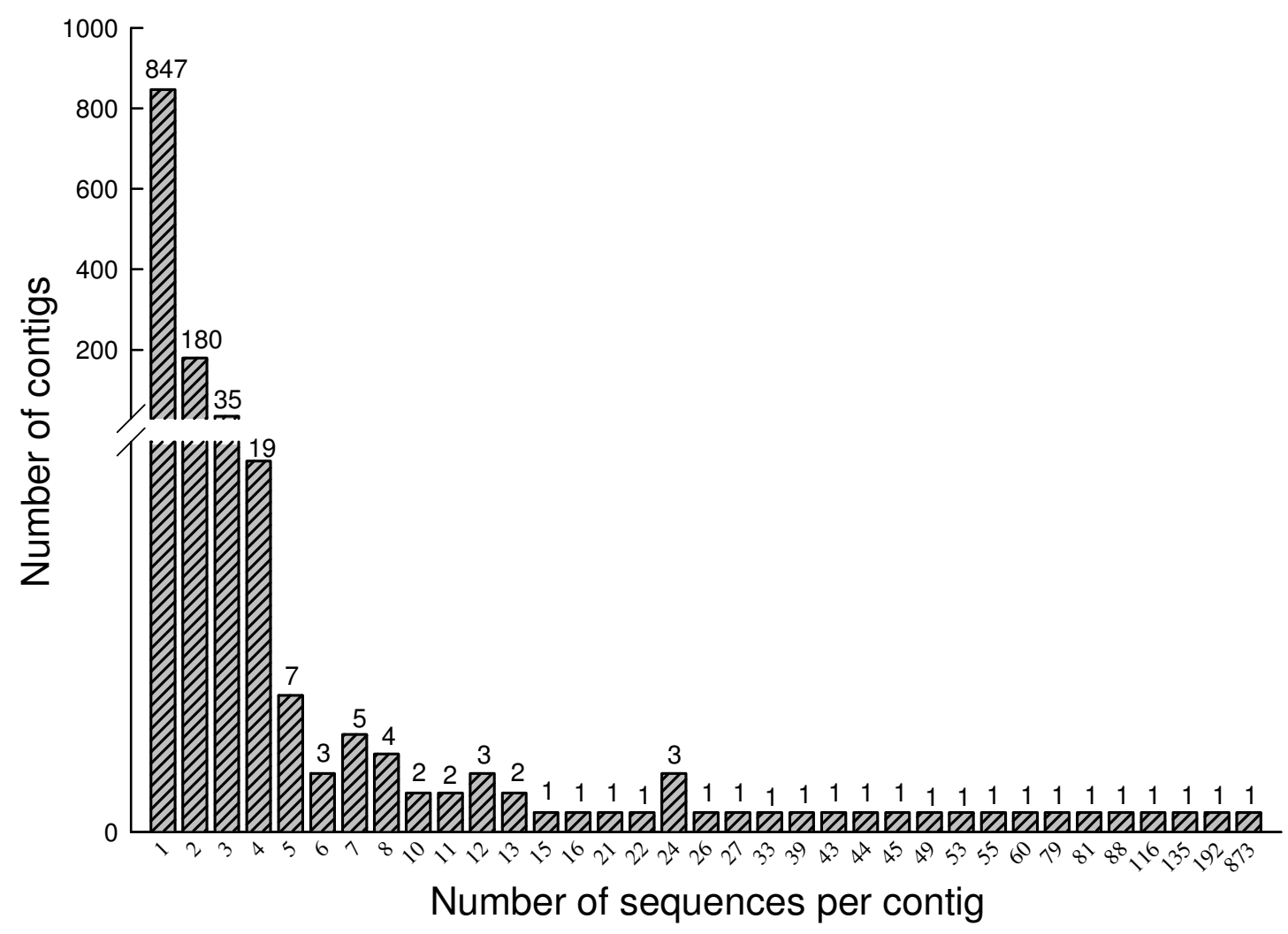

Figure I

Frequency distribution of sequences from the haustorial cDNA library of Puccinia striiformis f. sp. tritici belonging to the same contig or unisequence. A total of I,I34 unisequences were used in this analysis

iniospores [16] and germinated urediniospores [17] deposited in the Genbank. Some had high homology to ESTs from a haustorium-specific cDNA library of $U$. fabae [15].

\section{Prediction of ESTs encoding secreted proteins}

To identify putative secreted proteins from the haustorial cDNA library, we selected unisequences that appeared to code for full-length open reading frames and predicted their translation products. Predicted proteins from open reading frames with in-frame stop codons before the start codon were analyzed with the signal P 3.0 algorithm [20] and iPSORT [21]. The analysis identified 15 unisequences encoding proteins with secretion signal peptides at the $\mathrm{N}$ terminus (Table 1 ). These sequences were predicted to encode proteins ranging in size from 56-289 amino acids. Seven of them did not show significant homology to known protein sequences, seven matched predicted proteins of unknown function and one had significant homology to sulfate transporters. Eight encoded Cys-rich proteins with more than 5\% cystein residues in the predicted protein.
Expression patterns of genes from haustorial cDNA library To examine developmental stage-specific gene expression, ten unisequences were selected from the haustorial cDNA library to assay their transcript levels during different developmental and infection stages through qRT-PCR. As determined by the GeNorm analysis, elongation factor-1, $\beta$-tubulin and actin showed $M$ values of $0.699,0.779$ and 1.838. Elongation factor- 1 was the most stable gene and was therefore used as a reference to normalize gene expression across different samples. Gene expression of the ten genes in uninfected wheat leaves, urediniospores, in vitro germinated urediniospores and infected wheat leaves was shown in Table 2. Among these genes, six were putative secreted proteins (PSTha2a5, PSTha12j12, PSTha5a23, PSTha12a4, PSTha12h2 and PSTha9F18). PSTha5a23 was specifically expressed in plants and was either not expressed in urediniospores and germinated urediniospores or expressed very weekly. Expression levels of PSTha2a5 and PSTha12j12 were weak in urediniospores, slightly increased in germinated urediniospores and high in Pst-infected leaves. PSTha12h 2 was expressed in all stages of development, with the highest levels in infected leaves. PSTha12a4 transcripts only 


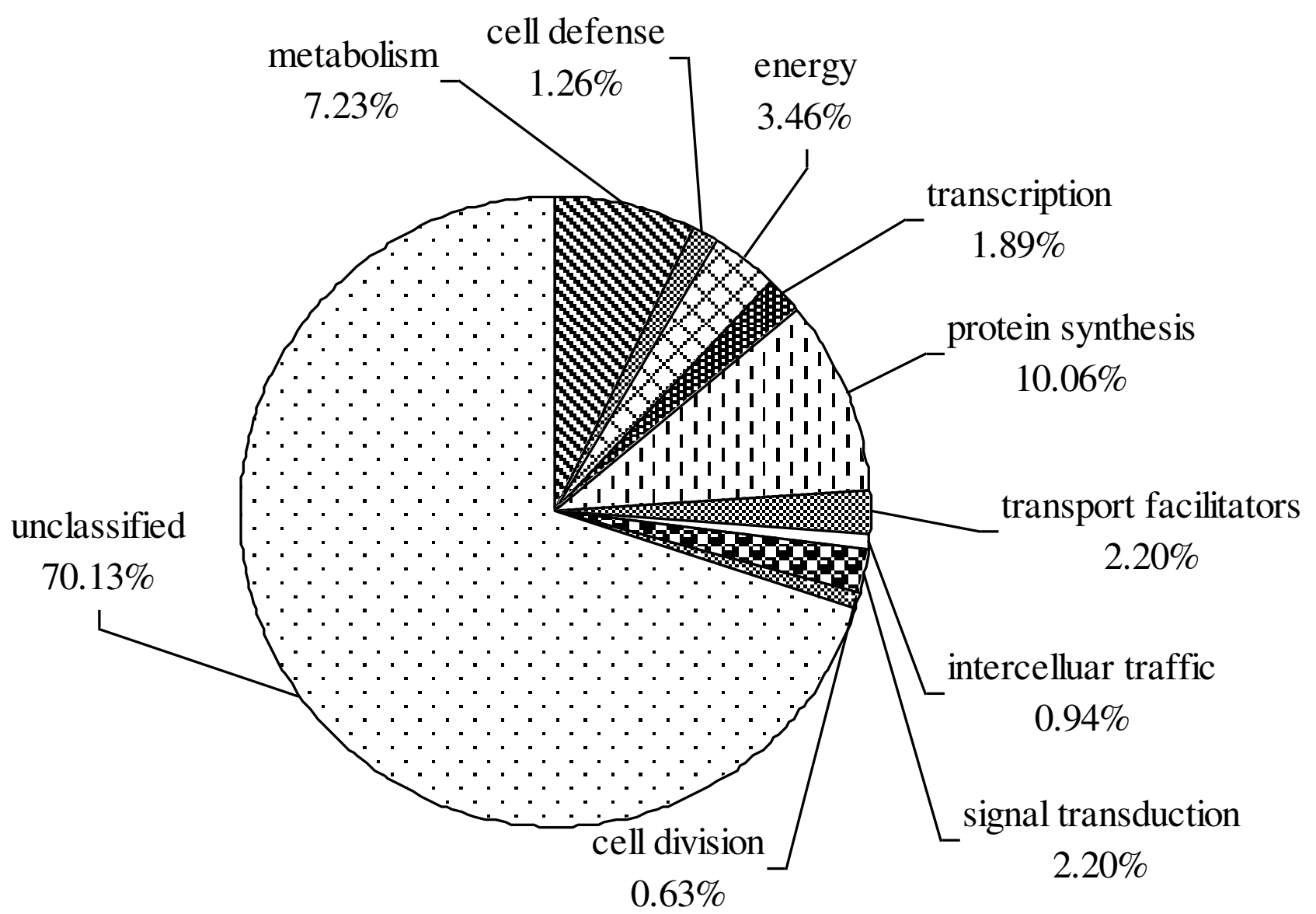

Figure 2

Functional classification of the Puccinia striiformis f. sp. tritici unisequence from the haustorial cDNA library showing significant similarities to proteins in public databases

Table I: Genes from the haustorial cDNA library of Puccinia striiformis f. sp. tritici predicted to encode secreted proteins

\begin{tabular}{|c|c|c|c|c|c|}
\hline Unisequence & GenBank accession & Size (aa) & No. of Cysteine residues & Homology in databases & E value \\
\hline PSTha2a5 & $\mathrm{GH} 737102$ & 117 & 6 & predicted protein of Puccinia graminis & $5.23 \mathrm{E}-23$ \\
\hline PSTha9FI8 & $\underline{\mathrm{GH}} 737274$ & 259 & 14 & hypothetical protein of Puccinia graminis & $8.96 \mathrm{E}-41$ \\
\hline PSTha I2a4 & $\mathrm{GH} 737444$ & 289 & 10 & predicted protein of Puccinia graminis & $4.00 \mathrm{E}-23$ \\
\hline PSTha $|2 j| 2$ & $\overline{\mathrm{GH} 737467}$ & 133 & 6 & no homology & - \\
\hline PSTha I5N2I & GH737567 & 98 & 7 & no homology & - \\
\hline PSTha2108 & $\mathrm{GH} 737139$ & 92 & I & putative sulfate transporter & I.42E-38 \\
\hline PSTha5a23 & $\underline{\mathrm{GH}} 737046$ & 108 & 4 & no homology & - \\
\hline PSTha6il 6 & $\mathrm{GH} 737950$ & 73 & 5 & predicted protein of Puccinia graminis & $3.00 \mathrm{E}-10$ \\
\hline PSTha8FI3 & $\underline{\mathrm{GH} 738007}$ & 116 & 6 & no homology & - \\
\hline PSTha2c7 & $\overline{\mathrm{GH} 737231}$ & 204 & 13 & predicted protein of Puccinia graminis & $1.15 \mathrm{E}-15$ \\
\hline PSTha I6B3 & GH737I29 & 87 & 2 & no homology & - \\
\hline PSTha I0F24 & $\overline{\mathrm{GH} 737323}$ & 56 & 3 & no homology & - \\
\hline PSTha I6D6 & GH737598 & 66 & 3 & hypothetical protein of Aspergillus niger & $2.00 \mathrm{E}-16$ \\
\hline PSTha9CI3 & $\underline{\mathrm{GH}} 738022$ & 65 & I & predicted protein of Puccinia graminis & $6.00 \mathrm{E}-10$ \\
\hline PSTha I 2 h2 & $\overline{\mathrm{GH} 737173}$ & 70 & 5 & no homology & - \\
\hline
\end{tabular}


Table 2: Expression of $P$. striiformis $f$. sp. tritici genes in different developmental stages

\begin{tabular}{|c|c|c|c|c|}
\hline \multirow[t]{2}{*}{ Unisequence } & \multirow[t]{2}{*}{ GenBank accession } & \multicolumn{3}{|c|}{ Relative expression } \\
\hline & & GerUred/Ured ${ }^{\mathrm{a}}$ & InfW/GerUred b & InfW/Uredc \\
\hline PSTha2a5 & $\mathrm{GH} 737102$ & $4.70 \pm 1.19$ & $25.81 \pm 9.88$ & $119.89 \pm 48.27$ \\
\hline PSTha $|2 \mathrm{j}| 2$ & GH737467 & $9.40 \pm 3.03$ & $11.40 \pm 3.06$ & $104.31 \pm 28.23$ \\
\hline PSThal Iil9 & $\overline{\mathrm{GH} 737527}$ & $0.55 \pm 0.10$ & $350.07 \pm 56.80$ & $192.38 \pm 41.06$ \\
\hline PSTha5a23 & $\overline{\mathrm{GH} 737046}$ & $3.15 \pm 0.70$ & $1165.64 \pm 229.00$ & $3617.32 \pm 607.41$ \\
\hline PSTha5al & $\overline{\mathrm{GH} 737242}$ & $3.09 \pm 0.54$ & $1948.90 \pm 238.26$ & $5980.69 \pm 867.12$ \\
\hline PSTha I 2a4 & $\mathrm{GH737444}$ & $5.70 \pm 2.87$ & $0.71 \pm 0.31$ & $3.68 \pm 1.22$ \\
\hline PSTha I 2 h2 & $\mathrm{GH} 737173$ & $0.47 \pm 0.05$ & $50.40 \pm 5.14$ & $23.48 \pm 3.10$ \\
\hline PSTha 9FI8 & GH737274 & $1.42 \pm 0.34$ & $8.1 \mathrm{IE}-04 \pm 1.42 \mathrm{E}-04$ & $1.14 \mathrm{E}-03 \pm 3.08 \mathrm{E}-04$ \\
\hline PSTha5GI9 & $\overline{\mathrm{GH} 737890}$ & $1.42 \pm 0.82$ & $0.2 \pm 0.11$ & $0.26 \pm 0.16$ \\
\hline PSThal $\ln 16$ & $\overline{\mathrm{GH} 737421}$ & $0.94 \pm 0.22$ & $0.22 \pm 0.06$ & $0.20 \pm 0.05$ \\
\hline
\end{tabular}

a ratio of expression in germinated urediniospores (GerUred) vs. expression in urediniospores (Ured)

$b$ ratio of expression in infected leaves ( $\mathrm{InfW}$ ) vs. expression in germinated urediniospores (GerUred)

c ratio of expression in infected leaves (InfW) vs. expression in urediniospores (Ured)

increased in germinated urediniospores but not in infected leaves. In contrast, PSTha9F18 was expressed strongly in urediniospores and germinated urediniospores, and its expression decreased dramatically in infected leaves.

The other four genes for which expression patterns were examined were a THI2P homolog (PSTha14i19), a calcium/calmodulin-dependent protein kinase 2 homolog (PSTha11n16), a predicted chitinase (PSTha5a1) and a ubiquitin ligase E3C homolog (PSTha5G19). PSTha14i19 was expressed with the highest level in infected leaves. PSTha14i19 was homologous to U. fabae PIG4, which was thought to be involved in vitamin B1 biosynthesis $[11,14,15]$. A similar in planta induced rust gene was also reported in $P$. triticina, a wheat leaf rust pathogen [22-24]. Transcripts for PSTha5a1 were detected only in plants, while PSTha5G19 and PSTha11n16 were down regulated in infected leaves. None of these genes had transcripts in uninfected wheat leaves (data not shown), indicating that they were indeed Pst genes.

\section{Discussion}

Haustoria are specialized structures that are formed within the living cell of a host by biotrophic fungal pathogens during infection. Previous analyses of haustorial transcripts from other rust fungi $[13-15,25]$ indicated that they are rich in sequences induced in planta and involved in virulence as well as other aspects of parasitism, like nutrient uptake. In the present study, we constructed a cDNA library from the wheat pathogen $P$. striiformis $\mathrm{f}$. sp. tritici haustoria. A total of 5,126 randomly chosen ESTs were generated which represented 1,134 unique transcripts once plant sequences were removed and redundancies eliminated. Most of the highly redundant sequences, like several coding for ribosomal proteins, were very similar to other fungal sequences in databases and/or sequences found in Pst urediniospore and germinated urediniospore cDNA libraries and a $U$. fabae haustorium-specific cDNA library [15-17]. Proteins involved in protein synthesis, primary metabolism and energy production were most prevalent in predicted proteins with known functions. Similar findings were also reported in other pathogenic interactions during infection [19,22,24]. Overall, the less redundant sequences were surprisingly unique, especially considering the database searches included nucleotide and predicted protein searches of the $P$. graminis $\mathrm{f}$. $\mathrm{sp}$. tritici genome sequence and nucleotide searches of the Melampsora larici-populina genome sequence. Approximately $64 \%$ of the 1,134 unique sequences did not show significant similarities to known genes in databases. The frequency of sequences with no matches would likely have been lower if the full sequence of the cDNAs were available; some sequences appeared mostly non-coding. However, this frequency was not only high compared to other fungi $[15,26]$ but also higher than that observed for Pst libraries made from urediniospores [16] or germinated urediniospores [17]. Avirulence proteins from eukaryotic plant pathogens described to date have indicated that they are diverse in function and have "novel" sequences with little sequence similarity to proteins of known function. If genes expressed in haustoria are more likely involved in virulence, which is probably more specific to particular fungal species, this might explain why a high percentage of genes expressed in haustoria share little or no sequence similarity to genes in other fungi.

Several of the haustorial transcripts were predicted to encode products homologous to potential virulencerelated proteins based on sequence comparison with other plant or animal pathogens. For example, PSTha15i2 was homologous to glutamine synthetase. Several studies have indicated that glutamine metabolism is important 
for the virulence of various pathogens [27-29]. Glutamine synthetase enzyme activities were detected in pathogenic species of Mycobacterium, but were not detected in nonpathogenic species, indicating that this activity is potentially involved in the pathogenicity [30]. The glutamine synthetase of $U$. fabae was more strongly expressed in planta than in germinated urediniospores [15]. PSTha15B19 is a putative $l p d$ gene encoding dihydrolipoyl dehydrogenase. The mutant of the lpd gene in Mycoplasma gallisepticum resulted in reduced virulence [31].

Several unisequences were candidates for genes encoding the key components of conserved signaling pathways. PSTha18c1, PSTha10L9 and PSTha12p13 were found to encode CAMP-dependent protein kinase type 2, protein ras-1 precursor and protein phosphatase PP2A regulatory subunit B, respectively. cAMP-dependent protein kinase pathway elements are remarkably conserved and effects on virulence have been the focus of many studies. In Cryptococcus neoformans, the cAMP signaling cascade is required for both melanin and capsule production, and mating filaments. All elements of the cAMP cascade are essential for the serum-induced switch of yeast to hyphal growth, which is important for the virulence of this fungus [32]. The cAMP cascade regulates pathogenicity of Ustilago maydis[33]. RAS proteins belong to the Rho family (a superfamily of GTPases). The ras 1 mutants of $C$. neoformans were avirulent in animals [34]. Protein phosphatase PP2A is involved in several signal transduction pathways. Disruption of $r g b 1$ gene, a subunit of $\mathrm{PP} 2 \mathrm{~A}$, in Sclerotinia sclerotiorum reduced pathogenesis [35]. Further investigations of these proteins in Pst haustoria would be necessary to elucidate their functions in the infection process.

The fifteen unigenes predicted to encode secreted proteins are likely the best candidates for genes involved in specific virulence. Many plant pathogens manipulate their hosts through delivery of effector proteins [36-39]. In contrast to host resistant proteins, rust and mildew avirulence gene products described to date often share no significant sequence similarity to proteins of known function [36]. About 30 Avr genes in the flax rust pathogen have been identified by genetic analysis [40]. Recently Ellis and coworkers identified 21 HESPS (haustorially expressed secreted proteins) genes by examining a $M$. lini haustorium transcripts for secretion signals [12]. Among these HESPS, three co-segregated with the independent AvrM, AvrP4 and AvrP123 loci. Transient expression assays have shown that these genes function as avirulence determinants to induce R gene-dependent cell death in flax [12]. This indicates that avirulence proteins are very abundant among proteins secreted from haustoria and thus the haustorial libraries are very useful tools for identifying them. In the present study, we identified 15 putative secreted proteins from haustoria. The sequences of these proteins provided few clues to their functions except for PSTha21O8, which had significant sequence similarity to a sulfate transporter. Understanding the functions of these genes should shed light on the mechanisms of Pst virulence and biotrophism. Ongoing efforts to establish methods for stable transformation and transient expression assays in this biotrophic fungus are therefore a high priority.

\section{Conclusions}

A cDNA library was constructed from RNA of haustoria isolated from Pst-infected wheat leaves. A total of 5,126 EST sequences of high quality were generated and assembled into 1,134 unique sequences. Approximately $64 \%$ of them showed no significant similarities in public databases, indicating that many are likely specific to certain Puccinia taxa and valuable for future genomic studies of the stripe rust pathogen. Most of the transcripts with known functions were predicted to encode ribosomal proteins involved in protein synthesis, followed by proteins of primary metabolism and energy production. Some of the unisequences were predicted to encode products that exhibited high similarities to proteins potentially associated with virulence from other fungi. The 15 haustoriumspecific genes predicted to encode secreted proteins are candidates for future studies to determine their potential functions in the wheat-Pst interactions.

\section{Methods}

\section{Plant genotypes and Pst isolates}

A wheat line carrying the $\mathrm{Yr} 8$ resistance gene in the 'Avocet Susceptible' background was inoculated with race PST-78 for production of spores and haustoria. Inoculation and culturing the host and pathogen was performed as described by Chen and Line [41]. To extract RNA from urediniospores, germinated urediniospores and infected wheat leaves, fresh urediniospores were harvested from infected leaves 15 days post inoculation (dpi). Urediniospores were germinated as previously described [17]. Briefly, fresh urediniospores were suspended in sterile distilled water in glass petri dishes and incubated in the dark for $12-15 \mathrm{~h}$ at $10^{\circ} \mathrm{C}$. Infected wheat leaves were harvested at 8 dpi with PST-78. Fresh urediniospores, germinated urediniospores, uninfected leaves and infected leaves were frozen in liquid nitrogen, and stored at $-80^{\circ} \mathrm{C}$ for further use.

\section{Isolation of Pst haustoria}

Haustoria were isolated from heavily infected wheat leaves at $8 \mathrm{dpi}$ (just prior to sporulation) using ConA affinity chromatography as described by Hahn and Mendgen [18]. Twenty-five $g$ of infected wheat leaves were gently washed with chilled distilled water and homogenized in $160 \mathrm{ml}$ of homogenization buffer [0.3 M sorbitol, 20 
mM MOPS pH7.2, 0.1\% BSA, 0.2\% 2-mercaptoethanol, $0.2 \%$ PEG 6000] using a blender at maximum speed for $10 \mathrm{~s}$. The homogenate was passed through a $20 \mu \mathrm{m}$ nylon mesh and centrifuged at 5,000 g for $5 \mathrm{~min}$. The resulting pellet was resuspended in $8 \mathrm{~mL}$ of suspension buffer. The suspension was centrifuged at 5,000 $\mathrm{g}$ for another $5 \mathrm{~min}$. The pellet was resuspended in $4 \mathrm{~mL}$ of suspension buffer. Two $2 \mathrm{~mL}$ aliquots of the suspension were loaded onto two columns each filled with 4-5 mL of a sepharose $6 \mathrm{MB}$ coupled to ConA. The columns were incubated for $15 \mathrm{~min}$ after the aliquots entered the columns. After extensive washing of the columns with suspension buffer, haustoria were released from the columns by agitation using a widebore sterile pipette. The binding and washing steps were repeated 3-4 times in fresh columns, until most of the chloroplasts had been washed away. The haustoria in the suspension buffer were then transferred to a $15 \mathrm{~mL}$ Eppendorf tube and centrifuged for $1 \mathrm{~min}$ at 10,000 $\mathrm{g}$ and the pellet frozen in liquid nitrogen and stored at $-80^{\circ} \mathrm{C}$. The whole process was carried out with reagents at $4^{\circ} \mathrm{C}$.

\section{Isolation of RNA}

For RNA isolation, fresh urediniospores, germinated urediniospores, infected leaves, uninfected leaves and haustorial cells were ground separately in a mortar in liquid nitrogen. Total RNA was isolated from frozen powder using the Qiagen Plant RNeasy kit (Qiagen, Chatsworth, GA) according to the manufacturer's instruction. For qRTPCR analysis, RNA samples were treated with DNase I and purified with phenol/chloroform. The absence of genomic DNA contamination was subsequently confirmed by the null PCR amplification of RNA samples with primers designed for the Pst $\beta$ tubulin gene and wheat GAPDH gene. The quantity and purity of isolated total RNA was analyzed by $2 \%$ agarose gel electrophoresis as well as by using a spectrophotometer.

Construction and sequencing of a haustorial cDNA library A cDNA library was prepared from $1 \mu \mathrm{g}$ of total RNA from haustoria using the SMART ${ }^{\mathrm{TM}}$ cDNA library construction kit (Clontech, USA) according to the manufacturer's instruction. The colonies were subsequently picked and arrayed into 384-well micro-titer plates. Each well on the culture plate contained $75 \mu \mathrm{L}$ of $\mathrm{LB}$ freezing storage medium [360 mM K $\mathrm{HPO}_{4}, 132 \mathrm{mM} \mathrm{KH}_{2} \mathrm{PO}_{4}, 17 \mathrm{mM} \mathrm{Na}$ citrate, $4 \mathrm{mM} \mathrm{MgSO}_{4}, 68 \mathrm{mM}\left(\mathrm{NH}_{4}\right)_{2} \mathrm{SO}_{4}, 44 \%$ (v/v) glycerol, $12.5 \mu \mathrm{g} / \mathrm{ml}$ of chloramphenicol, $\mathrm{LB}]$. Colonies were incubated at $37^{\circ} \mathrm{C}$ overnight, and then stored at $-80^{\circ} \mathrm{C}$. Prior to sequencing, 52 clones were randomly picked to check for the presence of inserts by colony-PCR using the

Table 3: Primers used in qRT-PCR analysis to determine expression patterns of ESTs from the Puccinia striiformis f. sp. tritici haustorial library in various developmental and infection stages

\begin{tabular}{|c|c|c|}
\hline Primer & Sequence(5' to 3 ') & Products size (bp) \\
\hline RT-PSTha2a5-F & TGAATGGGTCGGTTGCCACAGATA & 180 \\
\hline RT-PSTha2a5-R & GGCCCAAAGGGAATGGTCGAATTT & \\
\hline RT-PSTha $|2 \mathrm{j}| 2-\mathrm{F}$ & GCTTCGTTCGGGATTCAAAGCAAC & 138 \\
\hline RT-PSTha I $2 \mathrm{j} \mid 2-\mathrm{R}$ & ACATCTTGGGAACAGGCAGTTTCG & \\
\hline RT-PSThal 4il 9-F & AAGTGCTCGAATGGGTCCTACCTT & 135 \\
\hline RT-PSThal4il9-R & TGTGACGTTCACTTAGCCGATCCA & \\
\hline RT-PSTha I 2h2-F & ACGTCAGTCAAAGATGTCGGCGAA & 120 \\
\hline RT-PSTha I 2h2-R & TTCCTATCAATTAGCGCGGGAGCA & \\
\hline RT-PSTha5a23-F & TTCCTACTCTGGCGACCAACATCA & 194 \\
\hline RT-PSTha5a23-R & AAATCCGACTGACCGACATCCGTT & \\
\hline RT-PSTha5al-F & ACCGTATCGAAAGTGGTGTACGCT & 82 \\
\hline RT-PSTha5al-R & TGTCGTCCATTGGTCCCATAGTGT & \\
\hline RT-PSTha I2a4-F & GTTCACCAAAGCCACCTTCAACCA & 128 \\
\hline RT-PSTha I 2a4-R & ATTAGACGGCGGCGTTCTTAGGAT & \\
\hline RT-PSTha9FI8-F & ATTCGAGATTAACGCGACCAACGG & 169 \\
\hline RT-PSTha9FI8-R & GAAAGGTCAATGACAACGGCGTCT & \\
\hline RT-PSTha5GI9-F & AGGTCTCGATTACCTTCCGCTTCT & 127 \\
\hline RT-PSTha5GI9-R & AAGAAAGATCGAAACCAGCACCAG & \\
\hline RT-PSThal InI6-F & TGGGCATCTTCAGCTAGTTGGACT & 181 \\
\hline RT-PSThal In I6-R & TCAACACATTCAGACCACCTCCGA & \\
\hline RT-EFI-F & TTCGCCGTCCGTGATATGAGACAA & 159 \\
\hline RT-EFI-R & ATGCGTATCATGGTGGTGGAGTGA & \\
\hline RT-GAPDH-F & CAACGCTAGCTGCACCACTA & 161 \\
\hline RT-GAPDH-R & TTCCACСTCTCCAGTCCTTG & \\
\hline RT-TUB-F & CCGATCAATTCACGGCCATGTTCA & 174 \\
\hline RT-TUB-R & AACССТСТTCAACTTCСТCGTCGT & \\
\hline RT-ACT-F & TGTCGGGTGGAACGACCATGTATT & 146 \\
\hline RT-ACT-R & AGCCAAGATAGAACCACCGATCCA & \\
\hline
\end{tabular}


M13 forward and reverse primers. cDNA clones were sequenced with primer seq1 (5' CGACTCTAGACTCGAGCAAG 3') from the 5'-end. Some clones with larger insert sizes were also sequenced with primer seq2 (5' AACAGCTATGACCATG 3') from the 3'-end using an ABI 3130-XL DNA sequencer.

\section{Sequence analysis and database searches}

Raw sequences were processed using cross-match [42], which resulted in the removal of poor quality sequences and vector sequences. Assembly of individual sequences into overlapping contigs was done as described [17]. Contaminating wheat sequences were removed from sequences by BLASTn of the NCBI non-redundant database and the 'dbEST_Others' (non-mouse, non-human) and BLASTX of the NCBI non-redundant protein sequences. The remaining ESTs were further compared with the NCBI non-redundant protein database and $P$. graminis $\mathrm{f}$. sp. tritici genomic database using the BLASTX and BLASTn program http://www.broadinstitute.org/ annotation/genome/puccinia graminis/Blast.html and Melampsora larici-populina genomic database using the BLASTn program http://genomeportal.jgi-psf.org/cgi-bin/ runAlignment. E-values of less than $10^{-5}$ were considered significant matches to database sequences.

\section{Secreted protein prediction}

To search for potential secreted proteins, the sequences from the haustorial cDNA library were analyzed with the SignalP 3.0 algorithm [[20], http://www.cbs.dtu.dk/serv ices/SignalP/]. To support the SignalP result, the protein sequences with predicted secretory signal peptides were also examined using iPSORT http://hc.ims.u-tokyo.ac.jp/ iPSORT/.

\section{Quantitative real-time PCR analysis}

Using $1 \mu \mathrm{g}$ of RNA isolated from fresh uninfected leaves, urediniospores, germinated urediniospores and infected leaves, reverse transcriptions were performed using superscript reverse transcriptase with an oligo (dT15) primer (Promega. Madison, WI. USA) according to the manufacturer's instructions. qRT-PCR was carried out using the Bio-Rad iQ5 Real-Time PCR system. Specific primers for each gene selected were designed using primer design software (Integrated DNA Technologies) and listed in Table 3. Real Time PCR was conducted in $20 \mu \mathrm{L}$ volumes using SYBR Green PCR master mix (sigma). PCR conditions used were $95^{\circ} \mathrm{C}$ for $15 \mathrm{~min}$, followed by 50 cycles of $95^{\circ} \mathrm{C}$ for $20 \mathrm{~s}, 55-60^{\circ} \mathrm{C}$ for $30 \mathrm{~s}$ and $72^{\circ} \mathrm{C}$ for $30 \mathrm{~s}$, followed by a melting curve program. To identify a housekeeping gene with minimal variability in different rust developmental and infection stages, a qRT-PCR assay was established for three candidate reference genes ( $\beta$ tubulin, elongation factor- 1 and actin) to analyze their transcription levels. Subsequently, the reference gene stability measures $(M)$ were calculated by using the GeNorm tool as previously described [43]. A minimum of three biologically independent samples were used for each developmental stage, and two technical replicates were performed on every sample. Standard curves were generated for each gene. The quantification of gene expression was performed using the relative standard curve method by comparing the data with the reference gene.

\section{Authors' contributions}

$\mathrm{CY}$ isolated haustoria, constructed the haustorial cDNA library, participated in EST sequence analysis, conducted qRT-PCR and drafted the manuscript; XC contributed materials and resources, and wrote and revised the manuscript; XW, QH and ZK contributed to EST sequencing and BLAST searches. SH conceived and coordinated the study, interpreted the data, and wrote and revised the manuscript. All authors read and approved the final manuscript.

\section{Additional material}

\section{Additional file 1}

Putative functions of expressed sequence tags from the haustorial cDNA library of Puccinia striiformis $f$. sp. tritici as determined by BLASTX searches of the NCBI database

Click here for file

[http://www.biomedcentral.com/content/supplementary/14712164-10-626-S1.XLS]

\section{Additional file 2}

Putative functions of expressed sequence tags from the haustorial cDNA library of Puccinia striiformis $f$. sp. tritici as determined by BLASTX searches of the P. graminis genome database Click here for file

[http://www.biomedcentral.com/content/supplementary/14712164-10-626-S2.XLS]

\section{Acknowledgements}

PPNS No.0524, Department of Plant Pathology, College of Agricultural, Human, and Natural Resource Sciences, Agricultural Research Center, Project no. WNPO0663, Washington State University, Pullman, WA 99164-6430. This research was supported in part by the III Project from the Ministry of Education of China (B07049). We thank Dr. Timothy Paulitz for critical review of the manuscript.

\section{References}

I. Chen XM: Epidemiology and control of stripe rust on wheat. Can J Plant Pathol 2005, 27:3 |4-337.

2. Stubbs RW, Roelfs AP, Bushnell WR: Stripe rust. In The Cereal Rusts: Diseases, distribution, epidemiology and control Volume II. Academic Press, Orlando, FL; 1985:61-I0I.

3. Chen XM, Moore MK, Milus EA, Long DL, Line RF, Marshall D, Jackson L: Wheat stripe rust epidemics and races of Puccinia striiformis f. sp. tritici in the United States in 2000. Plant Dis 2002, 86:39-46.

4. Chen XM: Challenges and solutions for stripe rust control in the United States. Austral J of Agri Res 2007, 58:648-655. 
5. Allen RE: A cytological study of Puccinia glumarum on Bromus marginatus and Triticum vulgare. J Agri Res 1928, 36:487-5।3.

6. Kang ZS: Ultrastructure of plant pathogenic fungi Beijing: China Science \& Technology Press; 1995.

7. Hahn M, Mendgen K: Signal and nutrient exchange at biotrophic plant-fungus interfaces. Curr Opin Plant Biol 200I, 4:322-327.

8. Mendgen K: Nutrient uptake in rust fungi. Phytopathology 198I, 71:983-989.

9. Staples RC: Nutrients for a rust fungus: the role of haustoria Trends in plant science 2001, 6:196-198.

10. Voegele RT, Mendgen K: Rust haustorium: Nutrient uptake and beyond. New Phytol 2003, 159:93-100.

II. Sohn J, Voegele RT, Mendgen K, Hahn M: High level activation of vitamin BI biosynthesis genes in haustoria of the rust fungus Uromyces fabae. Mol Plant Microbe Interaction 2000, 13:629-636.

12. Catanzariti AM, Dodds PN, Lawrence G], Ayliffe MA, Ellis JG: Haustorially-expressed secreted proteins from flax rust are highly enriched for avirulence elicitors. Plant Cell 2006, 18:243-256.

13. Dodds PN, Lawrence G], Catanzariti AM, Ayliffe MA, Ellis JG: The Melampsora lini Avr567 avirulence genes are expressed in haustoria and their products are recognized inside plant cell. Plant Cell 2004, 16:755-768.

14. Hahn M, Mendgen K: Characterization of in plant-induced rust genes isolated from a haustorium-specific cDNA library. Mol Plant Microbe Interact 1997, 10:427-437.

15. Jakupovic M, Heintz M, Reichmann P, Mendgen K, Hahn M: Microarray analysis of expressed sequence tags from haustoria of the rust fungus Uromyces fabae. Fungal Genet Biol 2006, 43:8-19.

16. Ling P, Wang MN, Chen XM, Campbell KG: Construction and characterization of a full-length cDNA library for the wheat stripe rust pathogen (Puccinia striiformis f. sp. tritici). BMC Genomics 2007, 8: I 45-158.

17. Zhang Y, Qu Z, Zheng W, Liu B, Wang X, Xue X, Xu L, Huang L, Han $Q$, Zhao J, Kang $Z$ : Stage-specific gene expression during urediniospore germination in Puccinia striiformis f. sp tritici. BMC Genomics 2008, 9:203-212.

18. Hahn M, Mendgen K: Isolation by ConA binding of haustoria from different rust fungi and comparison of their surface qualities. Protoplasma 1992, 170:95-103.

19. Broeker K, Bernard F, Moerschbacher BM: An EST library from Puccinia graminis f. sp. tritici reveals genes potentially involved in fungal differentiation. FEMS Microbiol Lett 2006, 256:273-28I.

20. Bendtsen JD, Nielsen $\mathrm{H}$, von Heijne $\mathrm{G}$, Brunak S: Improved prediction of signal peptides: SignalP 3.0. J Mol Biol 2004, 340:783-795.

21. Bannai H, Tamada Y, Maruyama O, Nakai K, Miyano S: Extensive feature detection of $\mathrm{N}$-terminal protein sorting signals. Bioinformatics 2002, 18:298-305.

22. Hu GG, Linning R, Mccallum B, Banks T, Cloutier S, Butterfield Y, Liu J, Kirkpatrick R, Stott J, Yang G, Smailus D, Jones S, Marra M, Schein J, Bakkeren G: Generation of a wheat leaf rust, Puccinia triticina, EST database from stage-specific cDNA libraries. Mol Plant Pathol 2007, 8:45I-467.

23. Rampitsch C, Bykova NV, McCallum B, Beimcik E, Ens W: Analysis of the wheat and Puccinia triticina (leaf rust) proteomes during a susceptible host-pathogen interaction. Proteomics 2006, 6: $1897-1907$

24. Thara KV, Fellers JP, Zhou JM: In planta induced genes of Puccinia triticina. Mol Plant Pathology 2003, 4:5I-56.

25. Voegele RT, Struck C, Hahn M, Mendgen K: The role of haustoria in sugar supply during infection of broad bean by the rust fungus Uromyces fabae. Proc Natl Acad Sci USA 200I, 98:8|33-8I38

26. Ebbole DJ, Jin Y, Thon M, Pan H, Bhattarai E, Thomas T, Dean R: Gene discovery and gene expression in the rice blast fungus, Magnaporthe grisea: analysis of expressed sequence tags. Mol Plant Microbe Interact 2004, 17:1337-1347.

27. Hava DL, Camilli A: Large-scale identification of serotype 4 Streptococcus pneumoniae virulence factors. Mol Microbiol 2002, 45: $1389-1406$.

28. Kloosterman TG, Hendriksen WT, Bijlsma JJ, Bootsma HJ, van Hijum SA, Kok J, Hermans PW, Kuipers OP: Regulation of glutamine and glutamate metabolism by $G \ln R$ and $G \ln A$ in Streptococcus pneumoniae. J Biol Chem 2006, 28 I:25097-25I09.
29. Lau GW, Haataja S, Lonetto M, Kensit SE, Marra A, Bryant AP, McDevitt $D$, Morrison DA, Holden DW: A functional genomic analysis of type 3 Streptococcus pneumoniae virulence. Mol Microbiol 2001, 40:555-571.

30. Raynaud C, Etienne G, Peyron P, Lanéelle MA, Daffé M: Extracellular enzyme activities potentially involved in the pathogenicity of Mycobacterium tuberculosis. Microbiology 1998, I 44:577-587

31. Hudson P, Gorton TS, Papazisi L, Cecchini K, Frasca S Jr, Geary SJ: Identification of a virulence-associated determinant, dihydrolipoamide dehydrogenase (Ipd), in Mycoplasma gallisepticum through in vivo screening of transposon mutants. Infect Immun 2006, 74:93I-939.

32. Fernandes L, Araújo MA, Amaral A, Reis VC, Martins NF, Felipe MS: Cell signaling pathways in Paracoccidioides brasiliensisinferred from comparisons with other fungi. Genet Mol Res 2005, 4:2|6-23I.

33. D'Souza CA, Heitman J: Conserved cAMP signaling cascades regulate fungal development and virulence. FEMS Microbiol Rev 200I, 25:349-364.

34. Waugh MS, Nichols CB, DeCesare CM, Cox GM, Heitman J, Alspaugh JA: Ras I and Ras2 contribute shared and unique roles in physiology and virulence of Cryptococcus neoformans. Microbiology 2002, | 48: | $9|-20|$.

35. Erental A, Harel A, Yarden O: Type 2A phosphoprotein phosphatase is required for asexual development and pathogenesis of Sclerotinia sclerotiorum. Mol Plant Microbe Interact 2007, 20:944-954.

36. Catanzariti AM, Dodds PN, Ellis JG: Avirulence proteins from haustoria-forming pathogens. FEMS Microbiol Lett 2007, 269:18I-188.

37. Collmer A, Badel JL, Charkowski AO, Deng WL, Fouts DE, Ramos AR, Rehm AH, Anderson DM, Schneewind O, van Dijk K, Alfano JR: Pseudomonas syringae Hrp type II I secretion system and effector proteins. Proc Natl Acad Sci USA 2000, 97:8770-8777.

38. Kamoun S: A catalogue of the effector secretome of plant pathogenic oomycetes. Annu Rev Phytopathol 2006, 44:41-60.

39. Petnicki-Ocwieja T, Schneider DJ, Tam VC, Chancey ST, Shan L, Jamir Y, chechter LM, Janes MD, Buell CR, Tang X, Collmer A, Alfano JR: Genomewide identification of proteins secreted by the Hrp type III protein secretion system of Pseudomonas syringae pv. tomato DC3000. Proc Natl Acad Sci USA 2002, 99:7652-7657.

40. Ellis JG, Dodds PN, Lawrence GJ: Flax rust resistance gene specificity is based on direct resistance-avirulence protein interactions. Annu Rev Phytopathol 2007, 45:289-306.

4I. Chen XM, Line RF: Inheritance of stripe rust resistance in wheat cultivars used to differentiate races of Puccinia striiformis in North America. Phytopathology 1992, 82:633-637.

42. Green Group [http://www.phrap.org/]

43. Vandesompele J, De Preter K, Pattyn F, Poppe B, Van Roy N, De Paepe A, Speleman F: Accurate normalization of real-time quantitative RT-PCR data by geometric averaging of multiple internal control genes. Genome Biol 2002, 3:RESEARCH0034.

Publish with Bio Med Central and every scientist can read your work free of charge

"BioMed Central will be the most significant development for disseminating the results of biomedical research in our lifetime. "

Sir Paul Nurse, Cancer Research UK

Your research papers will be:

- available free of charge to the entire biomedical community

- peer reviewed and published immediately upon acceptance

- cited in PubMed and archived on PubMed Centra

- yours - you keep the copyright 